\title{
Influence of the Coolant Flow Containing Silver Nanoparticles (Ag) from an Aqueous Solution Based on Ethylene Glycol (EG50\%) on the Thermal-Hydraulic Performance of an Automotive Radiator
}

\author{
Luiz Carlos Cordeiro Junior, Élcio Nogueira* \\ Department of Mechanics and Energy, FAT/UERJ, Resende, Brazil \\ Email: *elcionogueira@hotmail.com
}

How to cite this paper: Cordeiro Junior, L.C. and Nogueira, É. (2020) Influence of the Coolant Flow Containing Silver Nanoparticles $(\mathrm{Ag})$ from an Aqueous Solution Based on Ethylene Glycol (EG50\%) on the Thermal-Hydraulic Performance of an Automotive Radiator. World Journal of Nano Science and Engineering, 10, 14-26.

https://doi.org/10.4236/wjnse.2020.101002

Received: February 12, 2020

Accepted: March 16, 2020

Published: March 19, 2020

Copyright $\odot 2020$ by author(s) and Scientific Research Publishing Inc. This work is licensed under the Creative Commons Attribution International License (CC BY 4.0).

http://creativecommons.org/licenses/by/4.0/

\begin{abstract}
A theoretical analysis of the influence of the flow of a coolant containing silver nanoparticle $(\mathrm{Ag})$ in an automotive radiator is presented. The coolant fluid is composed of water or an aqueous solution of Ethylene-Glycol (EG50\%) and silver nanoparticles. Ethylene glycol (EG) has been used in automobile radiators for many years due to its compatibility with metals and its anti-cooling properties. Silver nanoparticles are being incorporated into the development of high-precision surgical equipment. It is shown that the rate of heat transfer increases significantly using silver nanoparticles and ethylene glycol and water. There is a maximum for heat exchange between fluids in all analyzed coolant flows-the maximum moves to higher airflow rates when the coolant flow rate is increased. However, the energy dissipation in the stream also increases, but the relationship between the energy dissipated in the flow and the energy transferred in the form of heat is low, which justifies the use of silver nanoparticles and ethylene glycol, or silver nanoparticles and water as a coolant in the automotive vehicle radiator.
\end{abstract}

\section{Keywords}

Automotive Radiator, Silver Nanoparticle, Water-Ethylene Glycol, Compact Heat Exchanger

\section{Introduction}

The electrical and thermal optical properties of silver nanoparticles are being 
incorporated into photovoltaic devices, biological, and chemical sensors. Conductive inks use silver nanoparticles for their high electrical conductivity, stability, and low sintering temperatures. The incorporation of silver nanowires is an exciting class of nanoparticles and is considered in possible applications of advanced technology [1].

Silver nanoparticles are used in clinical practice as antimicrobial and antifungal agents, in the coating of medical devices (catheters) and as a dressing component [2].

The development of nontoxic nanocomposite hydrogels containing silver nanoparticles is an active area of research, and the synthesis of silver nanoparticles in microgels and hydrogels using various chemical methods has been documented in the literature [3].

Silver nanoparticles are one of the most vital and fascinating nanomaterials among several metallic nanoparticles that are involved in biomedical applications and other areas, including medical, food, health care, and industrial purposes [4].

Remziye Güzel and Gülbahar Erdal present the methods of synthesis of silver nanoparticles in applications of electronic irradiation, laser ablation, chemical reduction, artificial biological techniques, photochemical processes, and microwave processing [5].

Automotive companies invest considerable resources in research of all types and techniques that can optimize the energy performance of automotive radiators [6].

M. J. Uddin et al. [7] demonstrated that nanofluids are designed by suspending medium-sized nanoparticles below $100 \mathrm{~nm}$ in traditional heat transfer fluids such as water, oil, and ethylene glycol. Nanofluids are considered to offer substantial advantages over conventional heat transfer fluids.

Kohl Kai Liang Peter [8] investigates whether using nanofluids as a working fluid, as opposed to water, will reduce pipe dimensions in an industrial facility. One conclusion he came to is that while nanofluids have great potential to replace water, there are still many obstacles to get through. On the one hand, the cost of producing a nanofluid is very high. The viscosity of nanofluids tends to increase with increasing volume fraction. Finally, specific heat capacity decreases with increasing volume fraction, making nanofluids less suitable for refrigeration applications.

Water is the most used heat transfer fluid, and however, in cooling systems, it may be necessary to mix water with ethylene glycol to decrease freezing point and prevent ice formation. In-car radiators or industrial heat exchangers, the boiling point of water, can be changed by mixing ethylene glycol-based fluids [9].

Ethylene glycol (EG) has been used as an antifreeze in automobile radiators for many years because of its compatibility with metals. The mixture of ethylene glycol and water in various ratios like 30:70,50:60, and 50/50, respectively, are 
mostly used in automobiles. However, the low thermal conductivity of the fluids is a concern. A new class of heat transfer fluid named "nanofluid" that has enhanced thermal conductivity superior to the respective base-fluid has been proposed. The thermal conductivity of nanofluids increases concerning concentration and temperature, which is highly desirable for heat transfer applications [10].

Manufacture of silver nanoparticles by repetitive irradiation of near-ultraviolet (UV) nanosecond laser pulses ( $355 \mathrm{~nm}, 5 \mathrm{ns)}$ in an aqueous silver nitrate solution in the absence of stabilizing agents was reported. Silver nanocubes (AgNCs) were found to increase in size with longer laser irradiation times [11].

The result of the correlation between the concentration of nanoparticles and the temperature gradient at the outlet of a tube with fluid containing nanometer-sized particles was presented. The base fluid is water reported. The $20 \mathrm{~nm}$ $\mathrm{Al}_{2} \mathrm{O}_{3}$ nanoparticle is mixed with base fluid with volume concentrations of $0.1 \%$, $0.2 \%$, and $0.5 \%$ [12].

A set of parametric studies of heat dissipation carried out in automotive radiators was presented. The objective was to determine, in a set of five heaters, which one had the best cooling performance. The researchers used the JB2293-1978 wind tunnel test method for automobile radiators and tractors. The results show that the higher the fin phase, the better the cooling performance and material savings [13].

Application of $\mathrm{CuO}$-water nanofluid with nanoparticle size of $20 \mathrm{~nm}$ and volume concentrations above $2 \%$ was presented. Chevrolet Suburban diesel engine radiator, under turbulent flow conditions, was analyzed numerically. The local convective heat transfer coefficients and the pumping power of the nanofluid flow in the heater were evaluated. The results show that the general heat transfer coefficient and the pumping power are, respectively, $10 \%$ and $23.8 \%$ more than that of the base fluid [14].

ÉLcio Nogueira [15] presents research on the addition of nanoparticles in a mixture of water and ethylene glycol considering, among others, Silver nanoparticles $(\mathrm{Ag})$ in a compact heat exchanger, finned flat tube type, used in automotive radiator. It was demonstrated that heat transfer rate using nanofluids could be up to 2.7 times higher than the use of ethylene glycol and water, or pure water, for relatively low airflow, and nanoparticle of silver has the most considerable influence. He demonstrates that the dynamic viscosity of the coolant increases with the volume fraction of ethylene glycol and that the kinematic viscosity of silver is significantly higher than the kinematic viscosity of water, ethylene glycol, and other nanoparticles used.

\section{Objectives}

To analyze the influence of the coolant flow containing Silver nanoparticles (Ag) from an aqueous solution based on ethylene glycol (EG50\%) on the thermal-hydraulic performance of an automotive radiator. 


\section{Methodology}

\subsection{Thermophysical and Geometrical Properties}

The experimental heat transfer rate and pressure drop were obtained by Ribeiro, L. N. [16] in the wind tunnel of Behr Brasil Ltda, a manufacturer of automotive radiators. The geometric specifications of the heater and air properties are represented by Tables 01 and 02 in Elcio Nogueira [15].

Thermophysical properties of base fluid and nanoparticles of Silver are presented in Table 1 below.

\subsection{Theoretical Analysis}

\subsubsection{Determination of Heat Transfer Rate}

The heat transfer rate depends on the overall heat transfer coefficient, which in turn depends on the heat transfer coefficients $h a$, and $h w$, on the airside and the waterside. To begin the calculations, it becomes necessary to determine the physical. However, the exit temperatures, in theory, are unknown a priori, and the average temperatures should be initially estimated.

With the initially stipulated input and output temperatures, defined physical properties, and the geometric quantities of the exchanger supplied, we have,

For the air:

$$
\begin{gathered}
G_{a}=\frac{m_{a}}{A_{\min }}=\frac{m_{a}}{\sigma_{a} A_{f r}} \\
R e_{a}=\frac{G_{a} D_{h a}}{\mu_{a}} \\
J=\frac{h_{a}}{G_{a} c_{p a}} P r_{a}^{2 / 3}
\end{gathered}
$$

The Prandtl number for air, $P r_{a}$, is obtained by interpolating the data, valid for air as the ideal gas, published by Çengel and Boles ([17], p. 934):

\begin{tabular}{|c|c|c|c|c|}
\hline SI & Property & $\begin{array}{c}\text { Water } \\
\mathrm{H}_{2} \mathrm{O}\end{array}$ & Ethylene Glycol EG50\% & $\begin{array}{l}\text { Silver } \\
\text { Ag }\end{array}$ \\
\hline 1 & $\begin{array}{c}k \\
\mathrm{~W} /(\mathrm{m} \cdot \mathrm{K})\end{array}$ & 0.605 & 0.4222 & 429 \\
\hline 2 & $\begin{array}{c}\rho \\
\mathrm{kg} / \mathrm{m}^{3}\end{array}$ & 1000 & 1058.33 & 10500 \\
\hline 3 & $\begin{array}{c}C_{p} \\
\mathrm{~J} /(\mathrm{kg} \cdot \mathrm{K})\end{array}$ & 4184 & 3879 & 235 \\
\hline 4 & $\begin{array}{c}\mu \\
\mathrm{kg} / \mathrm{m} \cdot \mathrm{s}\end{array}$ & $4.78 \cdot 10^{-4}$ & $9.809 \cdot 10^{-4}$ & - \\
\hline 5 & $\begin{array}{c}\mathcal{\vartheta} \\
\mathrm{m}^{2} / \mathrm{s}\end{array}$ & $10^{-6}$ & $0.9268 \cdot 10^{-6}$ & - \\
\hline 6 & $\begin{array}{c}\propto \\
\mathrm{m} 2 / \mathrm{s}\end{array}$ & $1.44 \cdot 10^{-7}$ & $1.0284 \cdot 10^{-7}$ & $1.74 \cdot 10^{-4}$ \\
\hline
\end{tabular}

Table 1. Thermophysical properties of Water-Ethylene Glycol based fluids and nanoparticle of Silver (Ag). 


$$
\begin{aligned}
\operatorname{Pr}_{a}= & 1.005351636 d_{0}+0.01292094145 \text { Tmed }_{a}+2.524174317^{-5} \text { Tmed }_{a}^{2} \\
& -5.074647769^{-8} \text { Tmed }_{a}^{3}+1.564763295^{-8} \text { Tmed }_{a}^{4}
\end{aligned}
$$

then,

$$
h_{a}=J \frac{G_{a} c_{p a}}{\operatorname{Pr}_{a}^{2 / 3}}
$$

For water-based nanofluid properties we have:

$$
\begin{gathered}
\rho_{\text {nano }}=\varnothing \rho_{\text {particle }}+(1-\varnothing) \rho_{w} \\
\mu_{\text {nano }}=\mu_{w}(1+2.5 \varnothing) \\
C p_{\text {nano }}=\left(\varnothing \rho_{\text {particle }} C p_{\text {particle }}+(1-\varnothing) \rho_{w} C p_{w}\right) / \rho_{\text {nano }} \\
k_{\text {nano }}=\left[\frac{k_{\text {particle }}+2 k_{w}+2\left(k_{\text {particle }}-k_{w}\right)(1-0.1)^{3} \varnothing}{k_{\text {particle }}+2 k_{w}\left(k_{\text {particle }}-k_{w}\right)(1+0.1)^{2} \varnothing}\right] k_{w} \\
\alpha_{\text {nano }}=\frac{k_{\text {nano }}}{\rho_{\text {nano }} C p_{\text {nano }}}
\end{gathered}
$$

where, Equation (7) is the Einstein equation, used for very dilute suspension, and $\emptyset$ is the volume fraction of nanoparticles.

Other quantities associated with the flow are obtained by:

$$
\begin{gathered}
R e_{\text {nano }}=\left[4\left(\frac{m_{\text {nano }}}{N_{\text {tubes }}}\right)\right] /\left(\pi D_{\text {hnano }} \mu_{\text {nano }}\right) \\
f_{\text {nano }}=\frac{64}{R e_{\text {nano }}} \text { for } R e_{\text {nano }} \leq 2100
\end{gathered}
$$

or

$$
f_{\text {nano }}=\left(0.79 \operatorname{Ln}\left(R e_{\text {nano }}\right)-1.69\right)^{-2} \text { for } R e_{\text {nano }}>2100
$$

Considering the flow regime of the Newtonian flow of a water-base nanofluid as completely developed, we have, for turbulent flow, approximately:

$$
N u_{\text {nano }}=0.023 \operatorname{Re}_{\text {nano }}^{0.8} \operatorname{Pr}_{\text {nano }}^{0.4}
$$

If the flow regime in the water-base nanofluid is laminar, it is used to interpolate the data of the Master Thesis of Nogueira, E. ([18], p. 130):

$$
\begin{aligned}
N u_{\text {nano }}=1.409019812 d_{0} Z_{\text {nano }}^{-0.3511653489} \text { para } 10^{-5} \leq Z_{\text {nano }}<10^{-3} \\
N u_{\text {nano }}=1.519296981 d_{0} Z_{\text {nano }}^{-0.335483303 d_{0}} \text { para } 10^{-3} \leq Z_{\text {nano }}<10^{-2} \\
N u_{\text {nano }}=10.8655-570.4671787 Z_{\text {nano }}+28981.67578 Z_{\text {nano }}^{2} \\
+950933.9838 Z_{\text {nano }}^{3}+20237498.47 Z_{\text {nano }}^{4}-276705269.6 Z_{\text {nano }}^{5} \\
+2340349265 Z_{\text {nano }}^{6}-1.112482493^{10} Z_{\text {nano }}^{7} \\
+2.269345238^{10} Z_{\text {nano }}^{8} \quad \text { para } 10^{-2} \leq Z_{\text {nano }} 10^{-1}
\end{aligned}
$$




$$
\begin{aligned}
N u_{\text {nano }}= & 5.261 d_{0}-19.93019048 Z_{\text {nano }}+139.4921627 Z_{\text {nano }}^{2} \\
& -605.9954034 Z_{\text {nano }}^{3}+1716.100694 Z_{\text {nano }}^{4}-3217.96875 Z_{\text {nano }}^{5} \\
& +3954.86111 Z_{\text {nano }}^{6}-3056.051587 Z_{\text {nano }}^{7}+1344.246031 Z_{\text {nano }}^{8} \\
& -256.2830687 Z_{\text {nano }}^{9} \text { para } 10^{-1} \leq Z_{w}=10^{0}
\end{aligned}
$$

Then, we have:

$$
h_{\text {nano }}=N u_{\text {nano }} \frac{k_{\text {nano }}}{D_{\text {hnano }}}
$$

It is necessary to determine the efficiency of the fin since there is a variation of temperature between the entrance of the plate of the exchanger (base of the fin) and its outlet:

$$
\eta=\frac{\operatorname{tgh}(m L)}{m L}
$$

at where

$$
m L=\sqrt{2 h_{a} / k_{a} t}
$$

The efficiency of the fin is determined by:

$$
\eta^{\prime}=\beta \eta+1-\beta
$$

at where

$$
\beta=\frac{\text { Fin area }}{\text { total area }}
$$

Then, we have:

$$
\frac{1}{U_{a}}=\frac{1}{\eta^{\prime} h_{a}}+\frac{1.0}{A_{\text {med }} K_{\text {aleta }}}+\frac{1}{\left(A_{w} / A_{a}\right) h_{\text {nano }}}
$$

at where

$$
A_{\text {med }}=\frac{A_{a}+A_{\text {nano }}}{2.0}
$$

and

$$
\frac{A_{w}}{A_{a}}=\frac{\text { water side heat transfer area }}{\text { air side heat transfer area }}
$$

By the theory of effectiveness ( $\varepsilon$-NUT) we have:

$$
N=N T U=\frac{A_{a} U_{a}}{C_{\text {min }}}
$$

The thermal capacities of air and nanoparticles water-based are calculated by:

$$
C_{a}=m_{a} * C p_{a}
$$

And

$$
C_{\text {nano }}=m_{\text {nano }} * C p_{\text {nano }}
$$

$C_{\min }$ is the lowest value between the thermal capacities of water and air.

$$
Q=\varepsilon C_{\min }\left(T_{h, a f}-T_{c, a f}\right)
$$




$$
\Delta T_{L n}=\frac{Q}{U_{a} A_{\text {total }}}
$$

and

$$
Q K_{\text {teo }}=\frac{Q}{\Delta T_{L n}}
$$

at where

$$
\varepsilon=1-\exp \left[\left(\frac{c_{\min }}{c_{\max }}\right)^{-1}(N T U)^{0,22}\left\{\exp \left[-\frac{c_{\min }}{c_{\max }}(N T U)^{0,78}\right]-1\right\}\right]
$$

according to Kakaç, S. ([19], p. 35).

$Q K_{\text {teo }}$ is the theoretical value for the ratio between the heat transfer rate in the air and the mean logarithmic temperature difference-MLTD.

With the heat transfer rate determined, as the first approximation, one can calculate the air and water exit temperatures, through the energy balance equations:

$$
Q=\varepsilon C_{\min }\left(T_{h, a f}-T_{c, a f}\right)
$$

and

$$
Q=m_{a} c_{p a}\left(T_{a, a f}-T_{a, e f}\right)
$$

The average outlet, air, and water temperatures can then be determined and compared to the initial set temperatures:

The mean air and water temperatures can then be determined and compared to the initially defined temperatures:

$$
T_{m, a}=\frac{T_{a, a f}+T_{a, e f}}{2}
$$

and

$$
T_{m, \text { nano }}=\frac{T_{\text {nano }, a f}+T_{\text {nano }, e f}}{2}
$$

The values obtained for the heat transfer rate were compared and, if they are outside of an appropriate value, when compared with experimental values or empirical expressions, the calculations for thermophysical properties can be re-started, until a satisfactory convergence is obtained for the problem.

\subsubsection{Determination of Dissipated Power in Nanofluid Flow}

$$
\begin{gathered}
\operatorname{Pot}_{\text {nano }}=\frac{m_{\text {nano }} \Delta P_{\text {nano }}}{N_{\text {tubes }} \rho_{\text {nano }}} \\
\Delta P_{\text {nano }}=\frac{8 f_{\text {nano }} L_{\text {tube }} Q_{\text {nano }}^{2}}{D h_{\text {nano }}^{5} \pi^{2} g} \\
\operatorname{Pot}_{\text {nano }}=Q_{\text {nano }} \Delta P_{\text {nano }}
\end{gathered}
$$

\section{Results and Discussion}

In all the cases analyzed in this work, the maximum coolant inlet temperature is 
equal to $100^{\circ} \mathrm{C}$, the maximum allowed outlet temperature for the coolant is equal to $95^{\circ} \mathrm{C}$. When the volume fraction of nanofluid is not specified, $\phi=0.05$.

Figure 1 shows the results of the air outlet temperature as a function of coolant flow rate, with the airflow rate as a parameter, with a volume fraction of silver nanoparticles equal to $\phi=0.05$ in aqueous Ethylene Glycol solution.

The outlet temperature of the air is lower when the heat exchanger contains a fraction of ethylene glycol with silver particles, for a given airflow rate. For higher airflow rates, lower values for the outlet air temperature. The outlet temperature of the air increases with increasing coolant flow rate, for a given airflow rate.

Figure 2 shows the results of the outlet temperature of the coolant as a function of the coolant flow rate, with the airflow rate as a parameter.

The outlet temperature of the coolant is lower when the heat exchanger contains a fraction of ethylene glycol with silver particles, for a given airflow rate. For higher airflow rates, lower values for the outlet coolant temperature. The outlet temperature of the coolant increases with increasing coolant flow rate for a given airflow rate. The heat transfer is less for a lower mass flow rate of the refrigerant, for a given airflow, because the refrigerant fluid stays longer in the tube and absorbs more heat for less airflow, less heat exchange, and the consequently higher refrigerant outlet temperature.

It is essential to highlight concerning Figure 1 and Figure 2: the outlet temperature of the air and the coolant fluid increases with the increase in the refrigerant flow rate, for a given airflow. The use of nanoparticles and ethylene glycol most significantly affects the outlet temperature of the refrigerant, improving thermal performance.

Figure 3 shows the results of the average temperature of the coolant as a function of the coolant flow, with the airflow as a parameter.

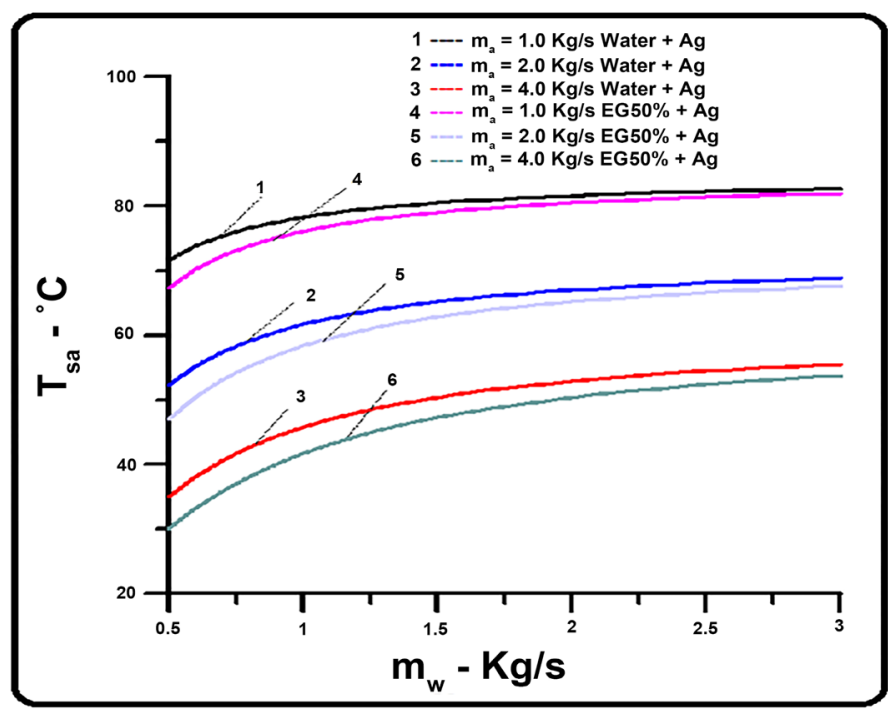

Figure 1. The temperature of the outlet air flow rate versus coolant flow rate. 


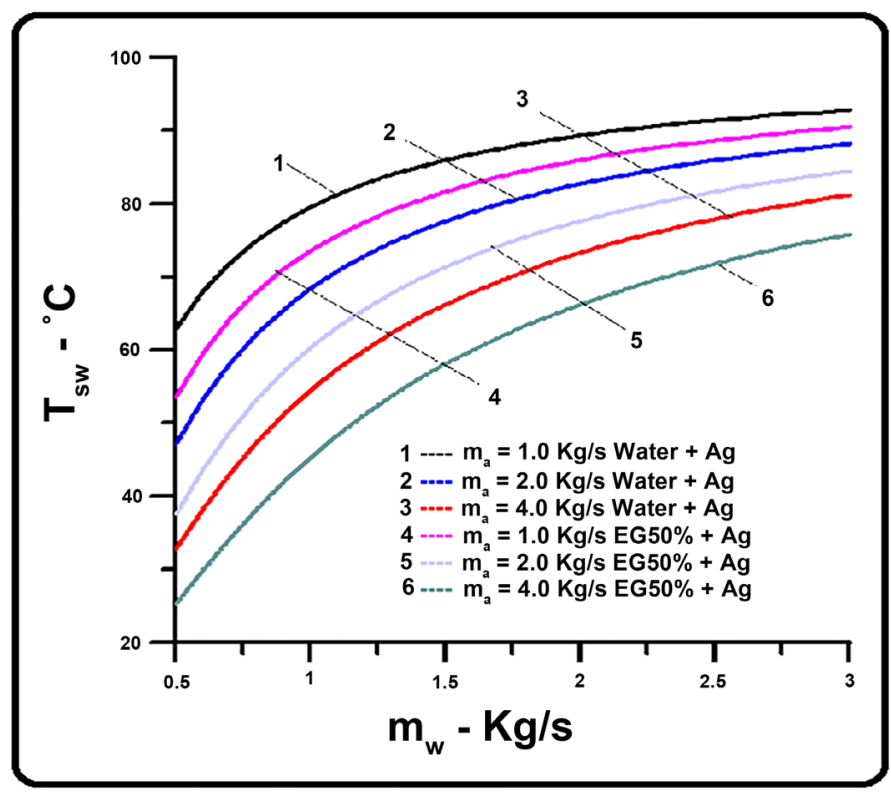

Figure 2. The temperature of the outlet coolant flow rate versus coolant flow rate.

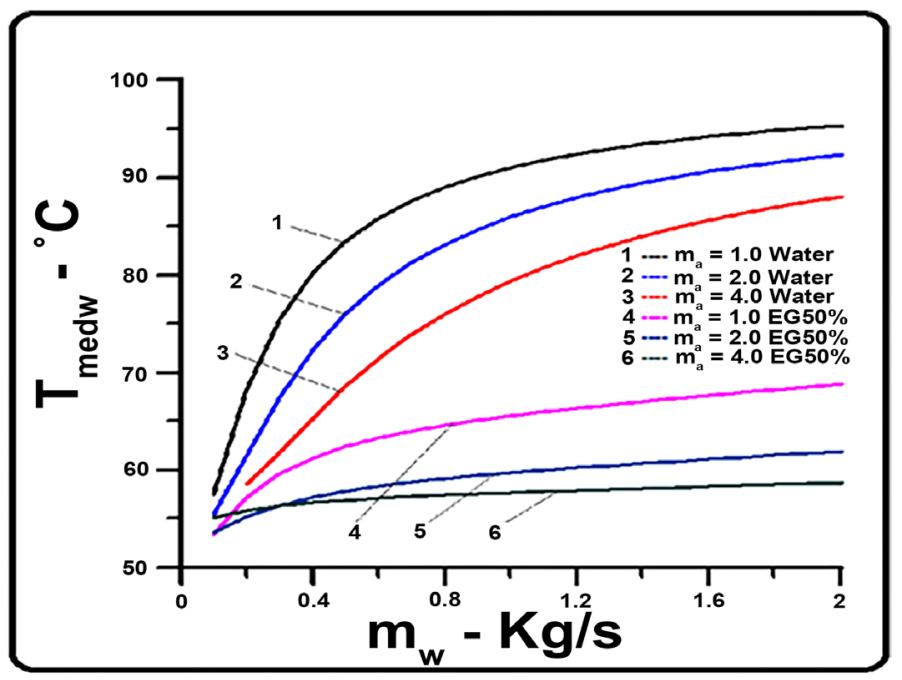

Figure 3. The average temperature of the coolant flow rate versus coolant flow rate.

The average temperature of the coolant is lower when the heat exchanger contains a fraction of ethylene glycol with silver particles, for a given airflow rate, because of the higher thermal diffusivity. For higher airflow rates, lower values for the outlet temperature. The average temperature of the coolant increases with an increasing coolant flow rate for a given airflow rate. It is observed, in this case, that when the airflow increases, the values of the average temperatures of the refrigerant fluid approach when using a given fraction of nanoparticle.

From the results observed in Figure 3, for airflow rates equal to $2.0 \mathrm{~kg} / \mathrm{s}$ and $4.0 \mathrm{~kg} / \mathrm{s}$ with nanoparticles, it is possible to anticipate that the indiscriminate increase in airflow does not lead to a better performance of the heat exchanger. 
It can be seen through Figure 4 that the heat transfer rate is higher for higher coolant flow rates, and that there is a maximum for heat exchange between the fluids, in all analyzed coolant flows-the maximum moves to higher airflow rates when the coolant flow rate is increased. There is no justification for increasing the airflow for given coolant flow, beyond the maximum heat transfer value.

In Figure 5, the heat transfer rate increases with the inclusion of Ethylene Glycol and a fraction of Silver particles for all airflow rates.

For higher values of airflow, the heat transfer does not suffer a significant increase, and in extreme situations, refrigerant flow rates equal to $8.0 \mathrm{~kg} / \mathrm{s}$ and 12 $\mathrm{kg} / \mathrm{s}$ there is a decrease in the heat transfer rate.

Similarly, to that observed in Figure 4, there is a limit for increasing the airflow.

Figure 6 and Figure 7 show results related to the dissipation of energy by the flow of the coolant.

As already noted by Élcio Nogueira [15], in Figure 6, it can be observed that there is a flow laminarization process with an increase in the volume fraction of the nanoparticles. For higher values of the volume fraction of the nanoparticles, the laminarization process occurs for more upper coolant flow rates. The laminarization process occurs because the absolute viscosity of the refrigerant is higher for the higher fractions of nanoparticles.

It can be seen through Figure 7 that there is no significant difference between the energy dissipation in the flow when comparing water flow and ethylene glycol without nanoparticles.

The energy dissipation in the flow increases with the volume flow rate of the coolant in all cases.

The power dissipated in the flow increases with the flow of the coolant, and with the increase in the fraction of silver nanoparticles.

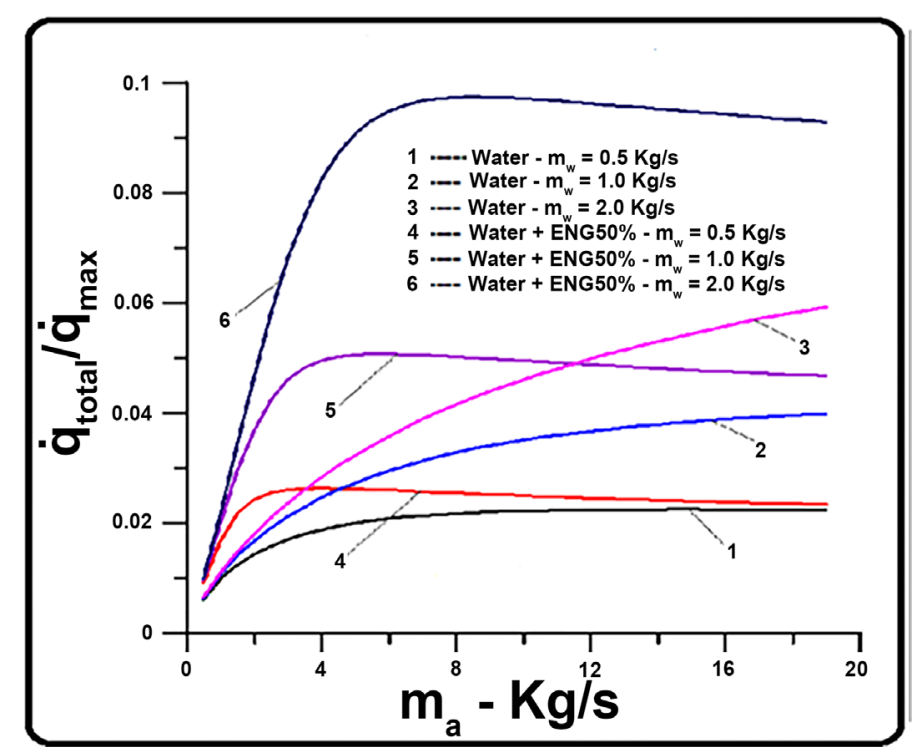

Figure 4. Dimensionalized heat transfer rate versus airflow. 


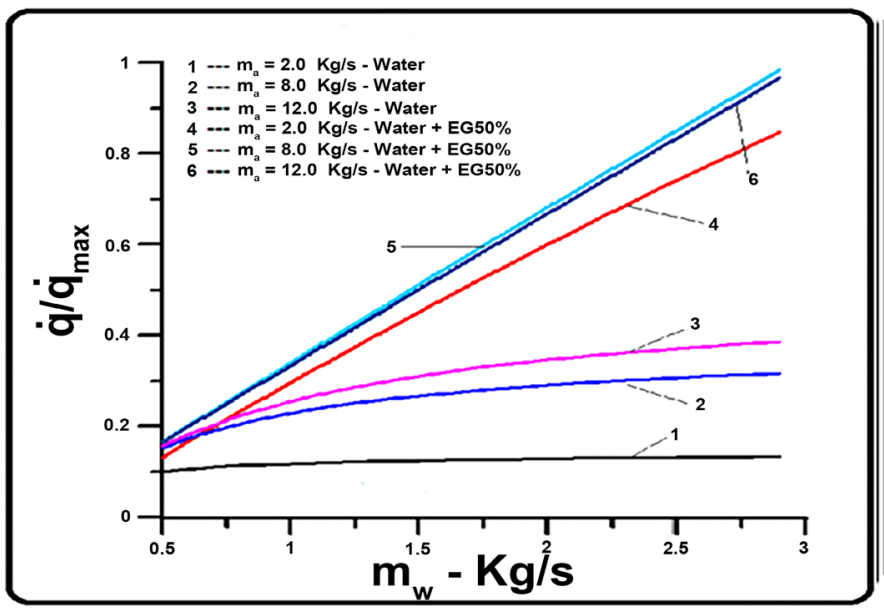

Figure 5. Dimensionalized heat transfer rate versus coolant flow rate.

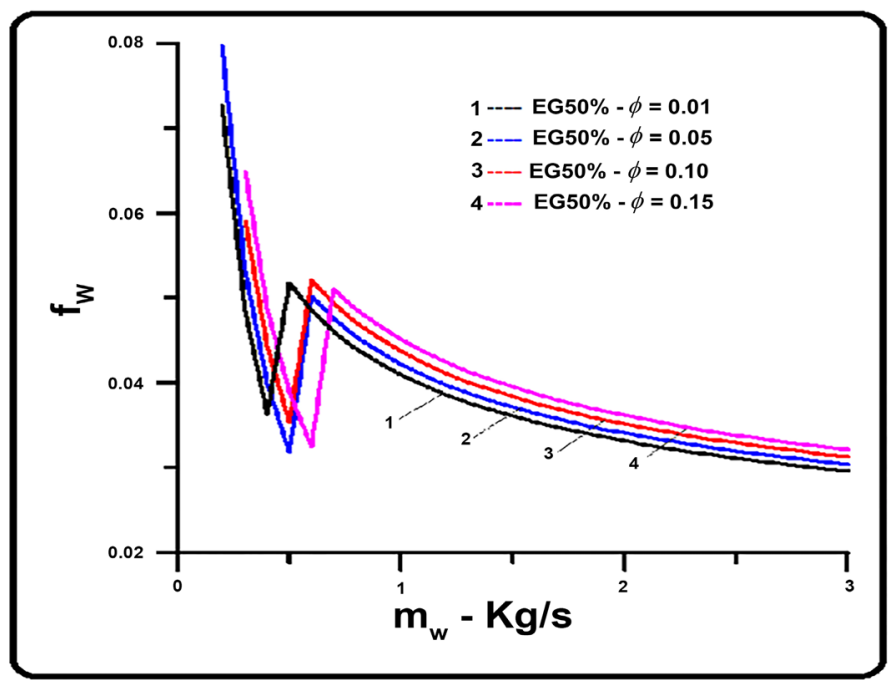

Figure 6. Friction coefficient versus coolant flow.

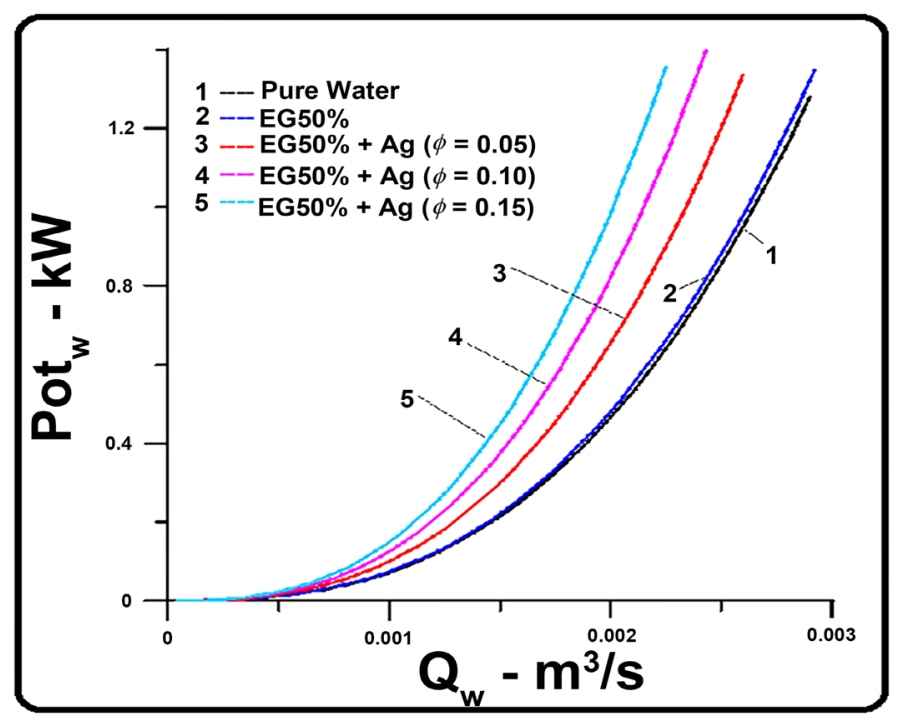

Figure 7. The power dissipated in the coolant flow versus volume flow. 


\section{Conclusions}

The results presented through theoretical, numerical, and graphic analysis demonstrate that the use of ethylene glycol associated with silver nanoparticles results in high thermal performance for automotive radiators, and the coolant flow rate has a significant influence on the results.

The results that corroborate the above conclusion are:

1) The outlet temperature of the air and the coolant fluid increases with the increase in the refrigerant flow rate, for a given airflow.

2) The use of nanoparticles and ethylene glycol most significantly affects the outlet temperature of the refrigerant, improving thermal performance.

3) The heat transfer rate is higher for higher coolant flow rates, and there is a maximum for heat exchange between the fluids, in all analyzed coolant flows-the maximum moves to higher airflow rates when the coolant flow rate is increased.

4) There is no justification for increasing the airflow for given coolant flow, beyond the maximum heat transfer value.

Regarding the hydraulic performance of the radiator, using ethylene glycol and silver nanoparticles, the following conclusions were reached:

1) There is a flow laminarization process with an increase in the volume fraction of the nanoparticles.

2) For higher values of the volume fraction of the nanoparticles, the laminarization process occurs for more upper coolant flow rates.

3) The power dissipated in the flow increases with the flow of the coolant, and with the increase in the fraction of silver nanoparticles.

\section{Conflicts of Interest}

The authors declare no conflicts of interest regarding the publication of this paper.

\section{References}

[1] Chouhan, N. (2018) Chapter 2. In: Maaz, K., Ed., Silver Nanoparticles-Fabrication, Characterization and Applications, IntechOpen, London, 21-58. http://dx.doi.org/10.5772/intechopen.71247

[2] Konop, M., Damps, T., Misicka, A. and Rudnicka, L. (2016) Certain Aspects of Silver and Silver Nanoparticles in Wound Care: A Minireview. Journal of Nanomaterials, 2016, Article ID: 7614753. https://doi.org/10.1155/2016/7614753

[3] Roshan Deen, G. and Chua, V. (2015) Synthesis and Properties of New "Stimuli" Responsive Nanocomposite Hydrogels Containing Silver Nanoparticles. Gels, 1, 117-134. https://doi.org/10.3390/gels1010117

[4] Zhang, X.-F., Liu, Z.-G., Shen, W. and Gurunathan, S. (2016) Silver Nanoparticles: Synthesis, Characterization, Properties, Applications, and Therapeutic Approaches. International Journal of Molecular Sciences, 17, 1534. https://doi.org/10.3390/ijms17091534

[5] Güzel R. and Erdal, G. (2017) Chapter 1: Synthesis of Silver Nanoparticles. In: Silver Nanoparticles-Fabrication, Characterization, and Applications, IntechOpen, London, 3-20. https://doi.org/10.5772/intechopen.75363 
[6] Pabón, N.Y.L. (2014) Design and Manufacture of a Wind Tunnel and Thermal Characterization of an Automotive Radiator. Dissertation Submitted to the Graduate Program in Mechanical Engineering of the Federal University of Santa Catarina to Obtain a Master's Degree in Mechanical Engineering.

[7] Uddin, M.J., Kalbani, K.S., Rahman, M.M., Alam, M.S., Al-Salti, N. and Eltayeb, L.A. (2016) Fundamentals of Nanofluids: Evolution, Applications, and New Theory. Biomathematics and Systems Biology, 2, 1-32.

[8] Koh Kai Liang Peter (2014) A Study on the Heat Transfer of Nanofluids in Pipes. Project Report MVK160 Heat Mass Transport, May 15, Lund.

[9] Nagulkar, N.S. and Lawankar, S.M. (2017) Improving the Cooling Performance of Automobile Radiator with Ethylene Glycol Water Based Zro2 Nanofluid and Compare with Al2o3 Nanofluid. International Research Journal of Engineering and Technology (IRJET), 4, 1255-1260.

[10] Selvam, C., Mohan Lal, D. and Harish, S. (2016) Thermophysical Properties of Ethylene Glycol-Water Mixture Containing Silver Particles. Journal of Mechanical Science and Technology, 30, 1271-1279. https://doi.org/10.1007/s12206-016-0231-5

[11] Qazi, U.Y., Shervani, Z., Javaid, R., Kajimoto, S. and Fukumura, H. (2017) Formation and Growth of Silver Nanocubes upon Nanosecond Pulsed Laser Irradiation: Effects of Laser Intensity and Irradiation Time. Advances in Nanoparticles, 6, 148-157. https://doi.org/10.4236/anp.2017.64013

[12] Bhuiyan, M.E.K., Khan, M.M.R. and Mahmud, I. (2017) Water Based Nanofluids: A Computational Study on Temperature Distribution in a Pipe Flow. Advances in Nanoparticles, 6, 141-147. https://doi.org/10.4236/anp.2017.64012

[13] Ismael, T., Yun, S.B. and Ulugbek, F. (2016) Radiator Heat Dissipation Performance. Journal of Electronics Cooling and Thermal Control, 6, 88-96. https://doi.org/10.4236/jectc.2016.62008

[14] Bozorgan, N., Krishnakumar, K. and Bozorgan, N. (2012) Numerical Study on Application of CuO-Water Nanofluid in Automotive Diesel Engine Radiator. Modern Mechanical Engineering, 2, 130-136. https://doi.org/10.4236/mme.2012.24017

[15] Nogueira, É. (2019) Thermal Performance of Ethylene-Based Aqueous Solutions Containing Silver $(\mathrm{Ag})$, Copper Oxide $(\mathrm{CuO})$, Aluminum Oxide (Al2O3) or Titanium Dioxide (TiO2) Nanoparticles in a Finned Flat Tube Compact Heat Exchanger (Automotive Radiator). The International Journal of Engineering and Science, 7, 56-59.

[16] Ribeiro, L.N. (2007) Optimization of Flat Fin Compact Heat Exchangers through Limit Layer Analysis. Dissertation Defended by the Department of Mechanical Engineering of Taubaté.

[17] Çengel, Y.A. and Boles, M.A. (2013) Thermodynamics. AMGH Editora Ltd., Porto Alegre.

[18] Nogueira, E. (1988) Laminar Flow and Heat Transfer in Immiscible Fluids without Stratification. Master Dissertation, Postgraduate Division of the Technological Institute of Aeronautics, São José dos Campos.

[19] Kakaç, S. (1991) Boilers, Evaporators, and Condensers. John Wiley \& Sons, New York. 